\title{
1. Entrepreneurship, social capital, governance and regional economic development: an introduction
}

\section{Charlie Karlsson}

The purpose of this book is to highlight the role of entrepreneurship, social capital and governance for regional economic development. Regional economic development is a multidimensional phenomenon, which has stimulated various authors to come up with their own definitions. In this introductory chapter we use the definition suggested by Stimson et al. (2006, 6): 'Regional economic development is the application of economic processes and resources available to a region that results in the sustainable development of, and desired outcomes for, a region and that meet the values and expectations of business, of residents and of visitors.' As all the other definitions of regional economic development in the literature, this definition is not perfect but it assists in the search for the role of entrepreneurship, social capital and governance as factors that underlie and drive the processes that support the sustainable development and competitiveness of regions. The strong relationship between regional economic development and entrepreneurship, social capital and governance, respectively, is clearly illustrated by Google Scholar, which on 20 September 2011, generated between 10000 and 15000 hits for each of the three combinations of these concepts.

\section{ENTREPRENEURSHIP AND REGIONAL ECONOMIC DEVELOPMENT}

The phenomenon of entrepreneurship has attracted much interest among researchers in different disciplines in recent decades (Kirzner, 1973; Drucker, 1985; Aldrich and Zimmer, 1986) and not least among researchers focusing on regional economic development (Alonso, 1968; Malecki, 1993; Amin, 1999; Markusen, 2004).

Myrdal (1957) presented one of the best-known theories of regional 
economic development - the cumulative causation theory. This theory has a clear market focus and emphasizes the processes by which certain regions are able to attract financial and human capital and thus accumulate a competitive advantage in relation to other less fortunate regions, where backward processes prevent the disadvantaged regions from developing their internal capacity to compete and grow. Some 40 years later Krugman (1995) stressed the importance of the same cumulative causation processes and their impact on the regional economic development processes. The same cumulative causation processes appear in the so-called new growth theory as self-reinforcing decline or growth processes. The new growth theory has a high significance for regional economic development through the explicit recognition of the role of entrepreneurship for initiating and driving the dynamic change processes (Karlsson et at., 2001; de Groot et al., 2004). This has been pointed out not least by Rees (2001), who stresses that technology-based theories of regional economic development need to incorporate the role of entrepreneurship, particularly as a factor in the endogenous growth of regions.

Porter (1990) and Ohmae (1995) claim that the most critical factor in sustaining regional economic growth is competitiveness, which is the single most important issue facing firms and regional policy makers in the future. Firms and regional development organizations must spend a significant amount of their time and resources on research and business intelligence to understand the general and specific factors such as entrepreneurship that generate competitiveness. They must scan their business environment regionally, nationally and internationally to understand potential threats and risks at different time horizons. In addition, they must anticipate and develop potential new markets that could be created through capitalizing on internal firm factors as well as regional factors that can generate a competitive advantage at the firm level as well as at the regional level.

The stress on the role of entrepreneurs in regional economic development is based on the idea that entrepreneurs have a key role in taking risks to get things done by developing new combinations of ideas and/or doing things differently, that is, by introducing innovations. Innovations will induce regional productivity and employment growth, that is, regional economic development, if they are successful. Regional entrepreneurship is driving regional structural change and economic rejuvenation by launching production techniques for producing existing products, which are more efficient, improved versions of existing products or new products in the regional market (Fritsch and Mueller, 2004). This will affect incumbent firms and force them either to fight the new firms with lower prices or better services and/or to improve their production techniques and their product portfolios. Successful new and growing firms will also increase 
the competition for factors of production, such as labour, facilities and land, making it necessary for incumbents to become more innovative to meet the increased costs. Thus innovations launched by entrepreneurs will induce imitation and further development of production processes and products by competitors, generating dynamic competition processes and stimulating further regional innovation.

We may distinguish two types of entrepreneurship: exploitative and explorative (see Breschi and Lissoni, 2001). Exploitative entrepreneurship is strongly rooted in existing practices and routines, and may even involve a direct imitation of an existing business idea simply placed in another context (Schmitz, 1989). Even if exploitative entrepreneurship is important not least for the spatial diffusion of innovations, its growth potential often is limited, since the product already exists in many markets. Explorative entrepreneurship, in contrast, stresses newness and a willingness to test new business ideas, that is, innovations, and offers opportunities for rapid upscaling of production since the product is new to the market. Researchers have in recent years tried to disentangle the effects of different types of entrepreneurship on regional economic development. It seems as if high-tech and knowledge-intensive start-ups in particular contribute to regional economic growth (Audretsch and Keilbach, 2004; Mueller, 2007). Similarly, Wong et al. (2005) stress that it is entrepreneurship based on the recognition of new business opportunities that governs economic growth. Thus the empirical evidence points in the direction that it is explorative entrepreneurship in particular that has beneficial effects on regional economic development. However, exploitative entrepreneurship may also be important, not least for establishing a regional competitive advantage based on spatially confined knowledge advantages (Schmitz, 1989). Entrepreneurial exploitation of unique but temporary knowledge advantages in a region may stimulate the emergence of a cluster of firms capable of generating location economies that can sustain the temporary knowledge advantages for a longer period.

The effects of entrepreneurship on regional economic growth can be disentangled according to effects on regional productivity growth and effects on regional employment growth. Starting with the former, most studies indicate a positive relationship between entrepreneurship and regional productivity growth (Karlsson and Nyström, 2007). However, the direct short-term effect of entrepreneurship on regional productivity seems to be limited. This is quite natural since the economic activities generated by new entrepreneurial endeavours are only a tiny share of the total regional economy. Furthermore, most of these endeavours are built on new product ideas, rather than new process ideas (Koster, 2006). Still, entrepreneurship has indirect positive influences on regional 
productivity growth. First, the threat of potential entries as well as actual entries forces incumbent firms to increase productivity. Second, new firms play an important role in the regional dissemination of knowledge, which can be of general importance for regional productivity growth (Koster and Karlsson, 2010). There are numerous studies that analyse the connection between firm entry, firm exit and regional productivity growth. ${ }^{1}$ Bosma and Nieuwenhuijsen (2002) analysed the effects of market turbulence, that is, entry and exit of firms, on total factor productivity (TFP) in Dutch regions. They found a positive relationship between turbulence and increased TFP in the service sector but no relationship in the manufacturing sector. Holtz-Eakin and Kao (2003) find a positive relationship between increased firm entry and growth of labour productivity in US states but no statistically significant relationship between firm exits and growth of labour productivity. Callejón and Segarra (1999), on the other hand, find a positive relationship between market turbulence and the growth of TPF in Spain. Braunerhjelm and Borgman (2004) have studied the importance of agglomeration advantages and regional entrepreneurship for growth of regional labour productivity in Sweden, and they find that both factors have a positive influence.

Policy makers are often more interested in the effects of entrepreneurship on regional employment growth than those on regional productivity growth. Hence researchers have devoted substantial efforts to analysing the employment side of regional entrepreneurship. Existing research results show that the regional employment effects of entrepreneurship vary over time as well as between the USA and Europe. The standard result in the USA seems to be that the relationship is positive (Acs and Armington, 2004). In Europe, on the other hand, some researchers found, particularly for the 1980s, a negative effect of entrepreneurship on regional employment growth (Fritsch, 1997; Audretsch and Fritsch, 2002, ${ }^{2}$ for Germany; van Stel and Storey, 2004, ${ }^{3}$ for the UK). However, other researchers have found positive regional employment effects of entrepreneurship for Europe (Ashcroft and Love, 1996, for the UK; Klette and Mathiasen, 1996, for Norway).

In order to develop a better understanding of the impact of entrepreneurship on regional employment growth, Fritsch and Mueller (2004) present a four-stage model, which is based on the idea that the regional employment effects of entrepreneurship follow a specific temporal pattern. Initially, entrepreneurship has a direct employment-generating effect. Even small firms offer employment, at least to the founder. Assuming that there exists unemployment and that at least some of the jobs previously occupied by the founders will be taken over by unemployed persons, a direct positive employment effect of entrepreneurship can be expected. However, after this initial stage, entrepreneurship might have negative 
effects on regional employment. Employment in incumbent firms might be negatively affected by increased competition from new firms. This is the face of creative destruction, when jobs in less efficient incumbent firms are displaced by jobs in new, more efficient firms offering products preferred by customers, often to the extent that some incumbent firms go out of business. In addition, several new firms will also go out of business during this phase due to inferior business ideas and/or bad management. After this stage, the regional employment effects become positive again in line with the Schumpeterian idea of development through entrepreneurship; that is, the overall efficiency of the regional economy increases, leading to employment growth. In the final stage, the regional employment effect of entrepreneurship in the base period fades away.

Evidence of such a wave-like pattern has been found for many countries, such as the UK (Mueller et al., 2007), Germany (Fritsch and Mueller, 2004), Portugal (Baptista et al., 2008) and the Netherlands (van Stel and Suddle, 2007). These studies also indicate that it often takes $8-10$ years before the full regional employment effects of entrepreneurship have matured (see Caves, 1998), and that the indirect employment effects can be more important than the direct employment effects. Fritsch and Mueller (2008) stress that the effect of entrepreneurship on employment can differ substantially between regions. The regional economic milieu in the form of density and regional productivity has a strong importance for the regional employment effect of regional entrepreneurship. In regions with low productivity, the employment effects of entrepreneurship can even be negative.

Summing up the theoretical arguments and empirical evidence presented in this section, we may draw the conclusion that entrepreneurship generally is critical for regional development. However, the new products launched by entrepreneurial endeavours are often, but not always, knowledge-intensive and/or high-tech, and that implies that not all regions offer a suitable economic milieu for explorative as well as exploitative entrepreneurship, including qualified customers with a high willingness to pay for new products with interesting characteristics.

To further regional economic development there is a need to foster entrepreneurship inside as well as outside existing firms. Policy makers can play a strategic role in fostering entrepreneurship by functioning as catalysts, by on the one hand pulling together resources and factors of production such as human capital and financial means, and on the other hand facilitating institutional change in such a direction that entrepreneurship becomes a more interesting alternative for individuals as well as groups of individuals. However, since regions differ substantially in terms of their economic milieu, there is a substantial need to tailor the policy initiatives to fit the specific circumstances of each individual region. 


\section{SOCIAL CAPITAL AND REGIONAL ECONOMIC DEVELOPMENT}

In recent years, the concept of social capital has attracted a great deal of interest among researchers in different academic fields such as economics, economic geography, management, political science and anthropology. This interest has been manifested on the one hand among politicians, policy makers and journalists, and on the other hand by some remarkable and path-breaking contributions by scientists such as Bourdieu (1980 and 1986), Coleman (1988 and 1990), Putnam (1988 and 1993), Portes (1998), Nahapiet and Ghoshal (1998) and Westlund (2006). These authors have connected, among other things, the effective performance of economies and democratic governance with strong norms of interpersonal trust and civic society. Building trust and consensual allocations of property rights generate norms valued by economic agents - norms that are key factors for transactions in goods, service and labour markets (Miller, 1992). Many activities and exchanges are such that economic agents have to rely on the future performance of other economic agents. Since it is in principle impossible to write complete contracts, economic agents have to rely on other measures to secure the right performance of other economic agents to secure low transaction costs. Mutual trust is one such measure that creates an economic environment where other economic actors' commitments are taken as credible and enduring. The role of social capital and, more precisely, the role of networks and trust in regional economic development have been highlighted by, among others, Malecki (1991), Morgan (1997), Rosenfeld (1997) and Amin (1999). However, the role of social capital in giving structure to regional economic development has traditionally tended to be neglected among most economists.

Social capital is a concept that has gained prominence as an approach to analysing the role of intangible factors such as trust, networks and institutions in regional economic development via not only comparative advantage but also via competitive advantage (Porter, 1986). The competitive advantage approach emphasizes that not only factor cost differentials are important but that also 'value factors' such as quality of life as well as human, cultural and social capital play a critical role for regional economic development. Some authors, such as Fukuyama (1995), claim that 'value factors' play an important role in the emergence of high-technology agglomerations, such as Silicon Valley, where cooperation between small and medium-sized firms through formal and informal networks and alliances, and connections with research universities generate an innovative climate through the combination of advanced R\&D, entrepreneurs and venture capitalists. Similarly, Saxenian (1994) stresses the role of cultural 
capital for the success of Silicon Valley by creating excellent opportunities for interaction with like-minded and diverse others.

Bourdieu and Wacquant $(1992,119)$ define social capital as 'the sum of the resources, actual or virtual, that accrue to an individual or group by virtue of possessing a durable network of more or less institutionalized relationships of mutual acquaintance and recognition'. According to this definition, social capital has two components: (i) a resource that is connected with group membership and social networks; and (ii) a quality produced by the totality of relationships between actors. The concept has also been formally defined by Coleman $(1988$, S98) as the factors that 'inhere[s] in the structure of relations between actors and among actors' and, according to him, 'Social capital is defined by its function. It is not a single entity, but a variety of different entities, with two elements in common: they all consist in some aspect of social structures, and they facilitate certain actions of actors within the structure' (ibid.).

Somewhat later, social capital was defined by Putnam $(1995,67)$ as all 'features of social life - networks, norms, and trust - that enable participants to act together more effectively to pursue shared objectives' ${ }^{4}$ Social capital is linked to economic development through several different mechanisms. The critical role of trust, cooperation and credible commitment for the effective functioning of markets and thus economic development is stressed in institutional economics (North, 1990; Miller, 1992) as well as in common pool resource economics (Ostrom, 1990). Economic development can also be influenced indirectly by social capital through its influence on government performance (Knack and Keefer, 1997).

Jacobs (1969) early on discussed the role of social capital for regional economic development. Many definitional extensions have been suggested in the literature, but as Malecki (1998) remarks, the concept is difficult to define and hence to measure and therefore to apply. Durlauf and Fafchamps (2006, 1642) make a statement in line with Malecki: 'While conceptual vagueness may have promoted the use of the term [social capital] among the social sciences, it also has been an impediment to both theoretical and empirical research of phenomena in which social capital may play a role.' There still exist substantial problems with the concept of social capital, even if many attempts have been made to operationalize the concept and to link it to national and regional economic development. Many of these studies claim to have found that differences in social capital between regions provide one credible explanation for differences in regional economic development (Putnam, 1993; Fukuyama, 1995; Knack and Keefer, 1997; Irwin et al., 1999; Tao and Feiock, 1999; Abel and Stough, 1999; Gulati and Gargiulo, 1999; Zak and Knack, 2001; Guiso et al., 2004; Ostrom, 2005; Chou, 2006; 
Antoci et al., 2007; Bartolini and Bonatti, 2008a, 2008b; Akcomak and ter Weel, 2009). ${ }^{5}$ However, the value of many of these studies is limited due to two main empirical problems (Sabatini, 2008): (i) the use of macro indicators, such as crime rates, teenage pregnancy, blood donation, participation rates in tertiary education and so on, which generate confusion about what social capital is as well as its relationship to the outcomes analysed (Durlauf, 1999); and (ii) the use of aggregated data without linkages with the social and historical circumstances in which trust, networks and social capital are located (Foley and Edwards, 1999; Fine, 2001). There is also a gap in the literature in the empirical studies of the effects of social capital on factors, such as human development and social cohesion, that might contribute to make economic growth sustainable in the long run. It is also unclear which types of networks have a positive effect on economic development. Sabatini (2008) finds that it is only 'linking' social capital that has a positive effect on human development and that 'bonding' and 'bridging' social capital have a negative effect on human development.

The importance of social capital stems from its capacity to reduce frictions considerably in market transactions in regional economic systems, that is, to reduce regional and local monitoring and transaction costs by nurturing trust and shared values. Such frictions are reduced in at least three ways (Malecki, 1998, 11):

- the creation of a system of general reciprocity;

- the establishment of information channels, providing sorted and evaluated information and knowledge, so-called buzz (Bathelt et al., 2004); and

- the simplification of market transactions through norms and sanctions by which economic exchanges can be facilitated, bypassing costly and legalistic institutional arrangements associated with market transactions.

By reducing frictions, social capital contributes to regional economic development by generating increasing returns in the regional economic system. Many authors view social capital as both a generator and a function of trust (Granovetter, 1985; Fukuyama, 1995). Even if trust is as difficult as social capital to define and to measure, it is viewed as a strategic component for making non-routine transactions with a minimum of friction. The capability of some regions, for example some so-called industrial districts, to maintain global competitiveness through networks of small and medium-sized firms, rather than being dependent upon one or several large firms, has in the literature in many cases been explained by high 
levels of trust among regional firms and organizations in the region, that is, a high level of social capital. Hence social capital is increasingly being viewed as a fundamental factor for regional competitiveness and thus for regional economic development, even if the evidence is mainly based on case study analyses or deductive reasoning. Existing studies indicate that regions with high levels of trust, and thus social capital, tend to be more competitive due to a better ability to adjust to the rapidly changing conditions that characterize the current era of global technology-led economic development (Stimson et al., 2006).

The implication of the above discussion for regional policy is that preserving and developing social capital becomes one major instrument to further regional economic development. Naturally, development of social capital is in most cases not a sufficient policy to generate regional economic development. Researchers have stressed, for example, the possibility to use the interrelation of social, environmental and cultural capital to support regional economic development (Krugman, 1995; Skott and Auerbach, 1995; Martin and Sunley, 1996; Galster, 1998). Such an approach implies that sustainable regional economic development should focus on actions that stimulate positive cumulative causation processes between the three types of capital that can generate increasing returns.

To summarize this section, we claim that it must be acknowledged that, even if there are issues regarding the definition and measurement of social capital, it has developed into one of the most critical factors for regional economic development policies in the modern global society. It is strongly related to the degree of trust between firms, organizations and individuals in a region, making it possible for them to reduce transaction costs both in market exchanges and in regional development projects. Regions with high social capital and trust seem to be able to initiate and execute regional economic development strategies and projects more easily and more effectively than regions with low social capital and low trust. Researchers have in recent decades tried to answer the question of how regions can enhance their social capital to stimulate regional economic development. Social capital has been linked to participation in social organizations (Putnam, 1993) and to civic education, which supports the development of norms of trust and cooperation (McGinn, 1996). However, the difficulties in defining, operationalizing, identifying and measuring social capital, networks and trust imply that more theoretical and empirical research is needed to better understand and design regional development policies that develop social capital and trust. It is our conviction that some of the contributions of this book provide new knowledge that contributes to such an improved understanding. 


\section{GOVERNANCE AND REGIONAL ECONOMIC DEVELOPMENT}

The question of governance of economic, social and political systems from the micro to the macro level has engaged researchers for a long time. In recent decades, we may observe the general contributions by Williamson (1979) and Rhodes (1996 and 1997) as well as the contributions focusing specifically on the governance of regional economic development by Luger and Goldstein (1991), Amin (1999) and McLeod and Goodwin (1999). 'Governance' should be understood in this connection as the act or manner or process of governing and the office or function of governing (Stimson et al., 2006). The issue of governance has increased in importance in recent decades, since economies at all levels - global, national and regional - have rapidly increased in complexity. Firms not only depend on their own capacity to cope with this increasing complexity, but also need to draw on other firms, in particular knowledge-intensive business service firms, and on public sector organizations as providers of inputs and services and as sources of learning and innovation (Helmsing, 2001). This implies that problems of coordination have multiplied in both the private and the public sector, while the uncertainties about the outcomes have increased. In order to deal with or at least reduce these and associated problems (such as asymmetric information asymmetries, information paradoxes, moral hazard, free-riding, lack of trust and opportunism), governance has become a critical issue.

Governance is an issue for all regions but it is particularly critical for those regions where coordination (and cooperation) is weakly developed and where more or less unregulated competition prevails (Scott and Storper, 1992). Especially the last group of regions face many problems and predicaments that compromise and threaten long-run viability and development. Such regions are all the more vulnerable because, in a global world with contested markets, their firms are faced with competitors based in regions that provide more efficient governance supporting coordination and cooperation within the region. In other words, the long-run economic development in a region depends as much on its firms as on the regional governance system and the interaction of the firms and the governance system to secure long-term coordination and cooperation. Governance systems that are better at handling these problems have a greater capacity for continuous adaptation and this allows them to maintain a long-term development trajectory. As economies are becoming more complex, new forms of governance need to be developed and implemented to secure coordination and cooperation both between firms and between firms and public sector organizations. 
Decisions by governments, firms and individuals concerning the collective and/or private use of resources and assets are in market economies governed by institutions, that is, commonly held principles, rules, values and so on, which define property rights and the level of transaction costs, and hence the efficiency with which different national and regional economies work. These institutions are, over time, slowly shaped, reinforced or changed by political decisions, custom, past experience and/or events elsewhere. The institutional framework of a society is critical since it determines its incentive structure (North, 1990, 4): 'Institutions, together with the constraints of economic theory, determine the opportunities of a society.'

The economic performance of a region over time is in a basic way influenced by existing institutions and the way they evolve over time, that is, how they reduce uncertainty, how they allow firms and individuals to have access to information, and how they reduce the market and policy imperfections that increase transaction costs. Clingermayer and Feiock (2001, 3) remark that institutions 'can provide the stability in collective choices that otherwise would be chaotic'. The nature of the institutional framework and the degree to which it imposes constraints or facilitates actions to identify, develop and explore opportunities can be seen as conditioning the innovation, entrepreneurship and investment processes that are essential for regional economic development (Vazquez-Barquero, 2002). The reason is that the institutional frameworks can (Stimson et al., 2006):

- reduce transformation and production costs;

- increase trust among economic and social actors;

- improve entrepreneurial capacity;

- increase learning and relational mechanisms; and

- reinforce networks and cooperation among actors.

The current era of globalization creates considerable challenges for governance of regional economic development including changes in institutional frameworks. We are experiencing the emergence of societies without clear borders with low friction for the movement of information, knowledge, people, goods, services, production and money. Governments and firms in today's world must be able to handle increasingly complex matters as well as greater levels of transparency and standardization because of stronger demands from different groups of stakeholders for greater transparency and accountability in government organizations. Furthermore, the role of governments at different levels is changing.

Governments in the global era of deregulation have less influence and control over regional economic development, including the investment 
and location decisions by firms, of which an increasing number are multinational. Thus governments at different levels need to learn how to facilitate and manage regional economic development processes so that they fit with the global forces that shape the patterns of investment and location of firms and households. Many governments have difficulties in accepting this situation. There are also often conflicts between governments at different levels, where not least regional governments demand greater empowerment and try to convince national governments (and supranational governments, such as the European Union) to delegate decision power and resources as well as to execute national policies in a consultative manner. At the same time, there is a growing tendency for new partnerships between national, regional and local governments, business organizations, trade unions, NGOs and so on to emerge with a mandate to execute many of the functions and responsibilities traditionally undertaken by government agencies.

The current globalization trends generate many paradoxes for national governments. They need on the one hand to develop national public policy and national public investments in public services, R\&D and infrastructures to stimulate innovation and entrepreneurship and to facilitate the growth of firms in a global context. However, on the other hand they need to empower regions and partnerships to mobilize resources to provide and manage those public services, $R \& D$ activities and infrastructures that are critical to support regional innovation and regional economic development. Thus governance processes and procedures are transformed, generating substantial challenges for governments to design new governance institutions.

The ongoing changes in the global economy have led to a relative decline in the role of the national governments and an increasing focus on regions as the real centres for innovation, entrepreneurship and regional economic development. Regions - and in particular the large metropolitan regions - dominate $R \& D$, innovation, entrepreneurship and investments, and have become the major creators of value added and employment growth. This implies that the functional metropolitan region to an increasing extent must become the geographic unit of both analysis and governance of regional policies, since they are the regions where most of the regional economic development is generated. However, often boundaries of the functional metropolitan region do not coincide with political and administrative boundaries, generating substantial governance problems, such as free-riding and lack of coordination in the provision of public services and infrastructures.

Many firms do not confine their economic activities to a specific region, not even in cases when they are integrated in strong industrial clusters. 
Instead, their economic activities in terms of production, exports, imports and so on are spread over many regions at home as well as abroad. Globalization, technological change and restructuring of regional and national economies have induced many firms to outsource activities to become more flexible and to be able to take advantage of economies of scale among suppliers. The globalization process and the destruction of the Soviet bloc has led to the integration of many developing economies in the world economy, which have opened up possibilities for firms in the developed countries to extend outsourcing to developing economies, that is, to offshore activities. This has led to the development of new business models, where not only manufacturing firms but also service, wholesale and retail firms take advantage of the new options and source inputs, products and services where they find the lowest production costs for a given quality level. What has emerged from this process is growing global networks of producers, suppliers, distributors and customers.

However, in the current knowledge-based, information-intensive era, regional economic development will not only be influenced by exogenous factors but increasingly by endogenous factors. We are moving globally into an age where firms and governments need to learn to anticipate and manage in a flexible manner emerging threats and opportunities and prevailing uncertainties rather than trying to determine or control future outcomes. Future economic outcomes will increasingly be managed through alliances and partnerships that combine ideas, values, information and knowledge rather than through big plans and interventionist policies. For regional policy makers this poses a great challenge to established systems of governance.

The processes discussed above have substantially changed the way firms and industries develop in a region and which location factors are critical. Governments that are not able to respond in the correct manner to these processes risk losing their position and becoming unattractive for expanding industries and firms. Many firms in the global economy are characterized to a high degree by foot-looseness; that is, they are free to locate their activities to those regions that offer the right type of business climate. The conclusion for the governance of regional economic development is that regional economic development strategies and policies must be cognizant of the global context of the region and develop regional actions in terms of provision of public services, $\mathrm{R} \& \mathrm{D}$ activities and infrastructures that facilitate integration with the global economy. It seems as if it is possible for many regions to create a path for the future by designing the required strategic architecture and to support a range of regional economic development possibilities, based on the competitiveness of resources, infrastructure, governance processes and core competence (Rosenberg, 1994). 
Regions need to have appropriate institutional arrangements to be able to design, fund and govern a regional development strategy, and to ensure the implementation of plans and actions (Blakely, 1994). Thus the capacity and capability of regional policy makers to govern, that is, to initiate, undertake and carry through plans and decisions for regional economic development is critically dependent upon the institutional framework. This implies that the development of the institutional framework is a fundamental factor in creating the right foundation for the governance of policies to further regional economic development.

\section{ENTREPRENEURSHIP, SOCIAL CAPITAL, GOVERNANCE AND REGIONAL ECONOMIC DEVELOPMENT}

Above, we have discussed three factors of critical importance for regional economic development, namely entrepreneurship, social capital and governance. However, we have mainly treated these three factors separately. This is of course a critical simplification. Regional entrepreneurship is certainly a function of, among other things, regional social capital and regional governance. Regional social capital, on the other hand, is, among other things, partly influenced by regional governance and the character and volume of regional entrepreneurship. Regional governance, lastly, is affected by regional social capital as well as by the character and volume of regional entrepreneurship. What must be observed in this connection is that regional social capital and regional governance structures and procedures change only slowly over time, since they are partly based on prevailing regional institutions. This implies that regional social capital and regional governance structures have the character of regional 'soft' infrastructure and that it may take substantial time for regions lacking social capital and with dysfunctional governance systems to correct for this. It must also be stressed that several elements of regional social capital are of such a character that they might be beyond what regional policy makers can influence even in the long run. In addition, it might also be difficult to influence the volume of regional entrepreneurship, since there seems to be a high degree of persistence in the regional rates of entrepreneurship (Andersson and Hellerstedt, 2009). What we can conclude is, first, that the relationships between regional entrepreneurship, regional social capital, regional governance and regional economic development are complex and interdependent. Second, to influence these factors and the relationship between them, policy makers must have a long-term perspective and be both patient and persistent in their efforts. 
It is our hope that the contributions making up the chapters of this book will provide both a somewhat better understanding of the relationships between regional entrepreneurship, regional social capital, regional governance and regional economic development and some help to national and regional policy makers in formulating and implementing the proper long-term regional policies needed.

\section{STRUCTURE AND CONTRIBUTIONS OF THIS BOOK}

The subsequent chapters of this book are arranged in a sequence starting with five chapters relating to entrepreneurship and regional economic development, followed by four chapters relating social capital to regional economic development and ending with five discussing issues related to governance and regional economic development.

In Chapter 2, Helen Lawton Smith and Saverio Romeo explore the relative contribution of long-established firms to the development of high-tech economies. They make a follow-up study of a study made 25 years ago of 182 high-tech firms employing about 10000 people. They find that almost two-thirds of the original firms still exist and that a number of them are now large employers. This is consistent with earlier studies, which have found that it is a minority of the firms that create the majority of jobs. This pattern is important from the viewpoint of regional economic development because of the greater potential impact of large firms on employment creation, recruitment and training, local purchasing power, knowledge spillovers, and engagement and leverage within local systems of governance when compared with small firms.

Gary A.S. Cook, Hans Lööf, Naresh R. Pandit and Börje Johansson address two questions in Chapter 3: (i) what, if anything, is the influence of geographic concentration of economic activity on patterns of foreign direct investments; and (ii) what is the relationship, if any, between geographic concentration of economic activity, multinationality and innovation? The authors identify the consensus view, which is emerging in the literature, based on both theory and evidence, that strong clusters are likely to be attractive for inward direct investment and that they promote innovation and test this relationship using data for the United Kingdom. They also address a surprising gap in the emerging literature by also examining the relationship between cluster strength and outward direct investment, thereby testing Porter's claim that advantages gained in strong clusters are the foundation for international competitiveness. Contrary to most of the emerging literature on international business, the authors 
make a distinction between two types of agglomeration economies: localization and urbanization economies. When examining the propensity to engage in outward direct investment and the geographic pattern of foreign ownership of firms active in the UK, the authors find that both are positively related to cluster strength, with localization economies being more important than urbanization economies. The evidence presented suggests that regional agglomeration promotes innovation and that localization economies are more important than urbanization economies.

Chapter 4 by Nunzia Carbonara seeks to contribute to the ongoing debate concerning the role of heterogeneity for the competitiveness of industrial districts. With this aim, the author focuses on different sources of heterogeneity and highlights how different levels of heterogeneity affect the performance of industrial districts. The chapter is based on empirical research conducted in 32 Italian district provinces. A cluster analysis methodology is applied to process the data collected in order to highlight whether there is a relation between the level of heterogeneity and the performance of district provinces and how the different levels of heterogeneity affect the district province performance.

Kristina Nyström in Chapter 5 starts from the well-known claim that entrepreneurship is important for generating employment and makes the observation that the empirical evidence on the relationship between entrepreneurship and employment is not always convincing. Most of the studies that analyse the relationship between new firm formation and employment growth perform their analysis on cross-country or regional data. However, according to the author, at the micro level, we still know little about the labour dynamics and reallocation effects induced by new firm formation. Against this background, the author asks which role do new firms play regarding labour reallocation. To answer this question, she explores the individual and firm characteristics for employees in new Swedish firms. Do new firm start-ups absorb outsiders in the labour market or do they recruit employees from existing incumbent firms? The author uses a unique matched data set for firms and employees that makes it possible to link new firm formation and information about the individuals employed in these firms. The empirical results indicate that the individual and firm characteristics associated with employees differ between new and incumbent firms. In particular, the share of immigrants, recent university graduates and people entering the labour market is slightly higher in new firms. Hence new firms might play an important role in helping outsiders to enter the labour market.

José Luis Crespo-Espert, Antonio García-Tabuenca and Federico Pablo-Martí in Chapter 6 analyse entrepreneurial activities among women. The presence of women in entrepreneurial activities is relatively recent. Academic research started to deal specifically with this issue halfway 
through the 1970s. From different social and academic forums, it has been persistently stated that entrepreneurial women show differences and/or discrimination by gender, and, although discrepancies exist (depending on the predominant culture and the ideas from which the analysis or the case study is approached), a great deal of research corroborates this. In general, four complementary viewpoints have been highlighted: personal features and motivations; leadership style and strategic choice of business; financing obstacles; and performance and results. This chapter goes into this area in depth by examining the behaviour of entrepreneurial women, adopting a regional focus and approaching the analysis in two ways: opinions provided in a survey regarding personal and business features of entrepreneurial women and men; and the results offered by the latter (women and economy average) on the basis of the financial information kept in commercial registries. Both views and their comparison by groups make it easier to draw some interesting conclusions, which in the chapter are contrasted with earlier research results in order to emphasize the most outstanding differences.

The study in Chapter 7 by Soogwan Doh and Edmund J. Zolnik explores the impact of social capital on entrepreneurship. The authors construct a measure of social capital that incorporates indicators of (i) trust (generalized and institutional), (ii) associated activities, and (iii) civic norms. Self-employment is used as a proxy for entrepreneurship. Before empirically testing the impact of social capital on entrepreneurship, the authors review the literature concerning the definition and measurement of social capital, the relationships between entrepreneurship and social capital, and explanations of how the different dimensions of social capital affect entrepreneurship. The results from the empirical model, which simultaneously controls for factors that according to theory, should affect entrepreneurship at the individual level, indicate that a positive relationship exists between social capital and entrepreneurship.

The aims of Chapter 8 by Hans Westlund are (i) to discuss empirical definitions of six theoretical dimensions of entrepreneurship, (ii) to make a first test of measuring them in the local governments in Sweden, (iii) to analyse whether the various dimensions of entrepreneurship are spatially connected to each other, and (iv) to investigate whether they are connected to local economic development. In line with much earlier research, he finds that economic entrepreneurship, measured by the number of start-ups per capita, is positively connected to local economic growth. A more interesting finding is that political/policy entrepreneurship by local governments is positively connected to growth in municipalities outside the metropolitan regions. Thus the actions of local governments seem partly able to compensate for weak market-led growth. 
Peter Stenberg and Mitchell Morehart in Chapter 9 observe that spatially dispersed economic actors in the USA have lower Internet penetration rates than their highly urbanized counterparts, either out of choice or from lack of local availability. To develop a better understanding of this divergence in Internet penetration, the authors use data from the Agricultural Resource Management Survey, the June Agricultural Survey, the Bureau of Census and the Federal Communication Commission broadband provider data to analyse American farms, a specific sector of spatially dispersed economic entrepreneurs. A majority of farms had Internet access, but only one-third of all farms used the Internet as an integral part of their management operations. In addition, broadband Internet use was lower for farms than for urban economic actors. In this chapter, the authors examine factors in Internet use and the technologies that farms use to get online. They show the difference in likelihood of broadband use with broadband provision and analyse the relative contribution of different factors through the use of logistic regression. The results suggest that availability of broadband Internet as well as the socioeconomic characteristics of the farm operator influence the adoption of broadband Internet for business purposes. Results also suggest that there is some pent-up demand for rural broadband services in the USA.

The emerging information society challenges relations between public agencies and citizens in many ways, as stressed by Iréne Bernhard and Elin Wihlborg in Chapter 10. Providing e-services on the Internet and using other forms of information and communication technologies are basic components of e-government. E-services as such are innovations - even if the service itself existed before - as they are a new way of producing and organizing the service. For secure and successful implementation of innovations in public contexts, the innovation must be considered legitimate and related to policies. The EU and all other levels of government in Europe form policies that are translated at the various levels to manage the useful, secure praxis of e-services. Translation in organizational terms takes place across government levels in the multi-level governance chain and secondarily from technical to administrative settings. Since the Swedish public administration relies on a dual steering approach, with strong, constitutionally mandated regional and local autonomy, such policies cannot be forced onto regional and local public agencies. Instead, European and national policy statements become soft policy instruments in the regional and local context, and their implications rely on regional and local uptake in the specific setting and on the competencies of the professionals in regional and local public administration. Since this is a new, emerging field of innovative policy and practice, the analysis in this chapter builds on an inductive methodological approach. The theoretical 
framework of policy and technology translation in this chapter allows inclusion of this broad process of changes. The focus in this chapter is on the translation process to highlight translations both across levels in multilevel settings and as constructions of meanings of security. The conclusion drawn in this chapter is that the organizational settings of multi-level governance are greater constraints than new technology for the implementation of public e-services.

When regional growth studies are conducted, there is a need for a good growth measure. There exist many growth measures, including growth of wage sum, population growth, growth of disposable income and so on. In Sweden, researchers also have access to growth of gross municipal product (GMP) as a growth measure. The aim of Chapter 11 by Tobias Arvemo and Urban Gråsjö is to compare theoretically and empirically growth of wage sum and growth of GMP as growth measures. Since the two measures are similar but not identical, the choice of growth measure can influence the conclusions of growth studies. Such studies might lead to, for example, contradictory results concerning how activities such as higher education and $R \& D$ influence economic growth. To highlight such possible effects, the authors have made an empirical study using Swedish data. They test whether or not the use of growth of GMP and growth of wage sum, respectively, in a regional economic growth model gives rise to different results. The data on GMP and wage sum growth at the municipal level is used to calculate two output measures: percentage change and percentage change per employee in two different periods. Local, intraregional and interregional accessibility to $R \& D$ are the main explanatory variables used in the model. The empirical results indicate that the models using any version of change in wage sum as dependent variable have more statistically significant parameters then the corresponding models using change in GMP.

Rural entrepreneurship depends on the availability of sufficient structures providing knowledge and skills, while the most effective training process for farmers is an education based on principles of experimental learning and adult education. Based on the results of nationwide research addressed to farmers, instructors and head trainers, Chapter 12 by Dimitrios G. Ierapetritis and Dimitrios Lagos explores and submits specific proposals for the reinforcement of entrepreneurship in the Greek rural areas. More specifically, the aim of this chapter is to highlight the main attributes of farmers who wish to engage in entrepreneurial activities in the secondary and tertiary sector, to explore the aspects of the educational and administrative resources in the Greek countryside, to reveal their educational needs for successful business ventures, and, finally, to put forward specific proposals both for promoting farmers' education and for the support of farmers who want to enter new business fields. 
Business support programmes in the USA, represented by small business development centres (SBDCs), business incubators and small business innovation research grants (SBIRs), play an important role in assisting new or small firms, nurturing entrepreneurial culture and facilitating regional growth. Previous studies have found that the presence of business incubators in a region is positively associated with the level of aggregation and negatively associated with the level of business development. It is, however, unclear whether the local knowledge context may influence the local presence of incubators. It is also unclear whether the other two business support programmes, that is, SBDCs and SBIRs, share similar geographic patterns with business incubators. Chapter 13 by Kingsley E. Haynes, Haifeng Qian and Sidney C. Turner focuses on these two uninvestigated questions and in particular examines the role of knowledge in shaping the geography of US business support programmes using county-level data.

Labour-intensive industries located in medium-high-cost areas are presently facing increasing low-cost competition and outsourcing, with tremendous employment consequences at the regional level. The ability to react and to adjust technologically to the challenges of these harder market conditions is what determines whether a region is a producer of high-value-added goods or a mere subcontractor. In fact, alternative employment opportunities may arise from complementary areas linked to technological innovations, and although one can expect further job decline in manufacturing production units, it is also possible that highqualification jobs may be created in complementary areas, such as design, marketing, retail and management. These issues are dealt with in Chapter 14 by Marisa Cesário and Maria Teresa de Noronha Vaz, which has two purposes. The first is to characterize the process of adoption of new technologies in the textile, clothes and leather sectors in a group of South European regions, characterized by their economic vulnerability and dependence on these sectors. The second purpose is to observe the impacts of technological change on local employment structures. The results reveal that these regions are in a process that is (i) developed internally, (ii) supplier dominated and (iii) motivated by the international market. Furthermore, the results indicate that firms investing in new plant and equipment and firms investing in the development of new products are more likely to be increasing employment than are other firms in these sectors. The authors conclude that alternative pathways for competitiveness in these industries can be found through higher productivity levels driven by a much-reduced workforce if a greater proportion of their turnover could be invested in new technology and increased qualifications among the labour force. 
Chapter 15 by Leo Paul Dana and Jan Åge Riseth is a study of reindeer herding in Finland. The authors identify important differences between indigenous Sámi reindeer herding and reindeer husbandry by persons from mainstream society. A central theme is that ethnic Finns simply view their entrepreneurship as a means to economic profit. In contrast, Sámi respondents attribute their herding to a 'pull' toward cultural tradition at the same time as another frequent finding was that Sámi respondents - especially women - were often 'pushed' into other activities to supplement their otherwise inadequate income derived from community-based reindeer herding. Policy reform in the form of entrepreneurship in politics, for example the adoption of a Nordic Sámi Convention, may be required to enfold the revealed cultural values into the sector legislation.

Per Assmo and Elin Wihlborg in Chapter 16 argue, based upon a timespace approach $\grave{a}$ la Hägerstrand, that the conventional market approach is not the most advantageous and best suited to understand the behaviour and choices of people. A crucial motivation for their argument is a fundamental dilemma with the conventional generalized economic growth approach, which simplifies and generalizes a complex time-spatial reality. According to the authors, the conventional monetary-based view of development is not suitable to understand and analyse the actual processes of change (development) conducted in local society. As a result, the possibility of identifying the unique characteristics, capacity and constraints of a place is concealed or even lost.

\section{NOTES}

1. It seems as if the contribution of firm dynamics to productivity growth increases with the period studied (Scarpetta et al., 2002).

2. However, they find a positive relationship for the $1990 \mathrm{~s}$.

3. These authors also find a positive relationship for the 1990s.

4. However, non-cooperative networks may under certain conditions be a hindrance to regional economic development (Knack and Keefer, 1997).

5. Some studies have found little support for a positive relationship between organizational activity and economic development (see, e.g., Jennings and Haist, 1998).

\section{REFERENCES}

Abel, T. and R.R. Stough (1999), 'Social capital and regional economic development', paper presented at the Southern Regional Science Association Meeting, 15-17 April, Richmond, VA.

Acs, Z.J. and C. Armington (2004), 'Employment growth and entrepreneurial activity in cities', Regional Studies, 38, 911-27. 
Akcomak, I.S. and B. ter Weel (2009), 'Social capital, innovation and growth: evidence from Europe', European Economic Review, 53, 544-67.

Aldrich, H. and C. Zimmer (1986), 'Entrepreneurship through social networks', in D. Sexton and R. Smilor (eds), The Art and Science of Entrepreneurship, Cambridge, MA: Ballinger, pp. 3-23.

Alonso, W. (1968), 'Urban and regional imbalances in economic development', Economic Development and Cultural Change, 17, 1-14.

Amin, A. (1999), 'An institutionalist perspective on regional economic development', International Journal of Urban and Regional Research, 23, 365-78.

Andersson, M. and K. Hellerstedt (2009), 'Location attributes and start-ups in knowledge intensive business services', Industry and Innovation, 16, 103-21.

Antoci, A., P. Sacco and P. Vanin (2007), 'Social capital accumulation and the evolution of social participation', Journal of Socio-Economics, 36, 128-43.

Ashcroft, B. and J. Love (1996), 'Firm births and employment change in British counties: 1981-1989', Papers in Regional Science, 75, 483-500.

Audretsch, D.B. and M. Fritsch (2002), 'Growth regimes over time and space', Regional Studies, 36, 113-24.

Audretsch, D.B. and M. Keilbach (2004), 'Entrepreneurship and regional growth: an evolutionary interpretation', Journal of Evolutionary Economics, 14, 605-16.

Baptista, R., V. Escária and P. Madruga (2008), 'Entrepreneurship, regional development and job creation: the case of Spain', Small Business Economics, 30, 49-58.

Bartolini, S. and L. Bonatti (2008a), 'The role of social capital in enhancing factor productivity: does its erosion depress per capita GDP?', Journal of SocioEconomics, 37, 1539-53.

Bartolini, S. and L. Bonatti (2008b), 'Endogenous growth, decline in social capital and expansion of market activities', Journal of Economic Behavior and Organization, 67, 917-26.

Bathelt, H., A. Malmberg and P. Maskell (2004), 'Clusters and knowledge: local buzz; global pipelines and the process of knowledge creation', Progress in Human Geography, 28, 31-56.

Blakely, E.J. (1994), Planning Local Economic Development: Theory and Practice, 2nd edn, Thousand Oaks, CA: Sage Publications.

Bosma, N. and H. Nieuwenhuijsen (2002), 'Turbulence and productivity: an analysis of 40 Dutch regions in the period 1988-1996', SCALES Paper N200205, EIM Business and Policy Research Zoetermeer.

Bourdieu, P. (1980), 'Le capital social', Actes de la Recherche en Sceinces Sociales, 31, 2-3.

Bourdieu, P. (1986), 'The forms of capital', in J. Richardson (ed.), Handbook of Theory and Research for the Sociology of Education, New York: Greenwood Press, pp. 241-58.

Bourdieu, P. and L. Wacquant (1992), An Invitation to Reflexive Sociology, Chicago, IL: The University of Chicago Press.

Braunerhjelm, P. and B. Borgman (2004), 'Geographical concentration, entrepreneurship and regional growth. Evidence from regional data in Sweden', Regional Studies, 38, 929-47.

Breschi, S. and F. Lissoni (2001), 'Knowledge spillovers and local innovation systems: a critical survey', Industrial and Corporate Change, 10, 975-1005.

Callejón, M. and A. Segarra (1999), 'Business dynamics and efficiency in regions: the case of Spain', Small Business Economics, 13, 253-71. 
Caves, R.E. (1998), 'Industrial organization and new findings of the turnover and mobility of firms', Journal of Economic Literature, 36, 1947-82.

Chou, Y.K. (2006), 'Three simple models of social capital and economic growth', Journal of Socio-Economics, 35, 889-912.

Clingermayer, J.C. and R.C. Feiock (2001), Institutional Constraints and Policy Choice: An Exploration of Local Government, New York: State University of New York Press.

Coleman, J.S. (1988), 'Social capital in the creation of human capital', American Journal of Sociology, XCIV, S95-S120.

Coleman, J.S. (1990), Foundations of Social Theory, Cambridge, MA: Harvard University Press.

de Groot, H., P. Nijkamp and R.R. Stough (eds) (2004), Entrepreneurship and Regional Economic Development: A Spatial Perspective, Cheltenham, UK and Northampton, MA, USA: Edward Elgar.

Drucker, P.F. (1985), Innovation and Entrepreneurship: Practice and Principles, New York: Harper and Row.

Durlauf, S.N. (1999), 'The case against social capital', Focus, $20,3$.

Durlauf, S.N. and M. Fafchamps (2006), 'Social capital', in P. Aghion and S.N. Durlauf (eds), Handbook of Economic Growth, Amsterdam: Elsevier, pp. 1639-99.

Fine, B. (2001), Social Capital versus Social Theory. Political Economy and Social Science at the Turn of the Millennium, London: Routledge.

Foley, M.W. and B. Edwards (1999), 'Is it time to disinvest in social capital?', Journal of Public Policy, 19, 199-231.

Fritsch, M. (1997), 'New firms and regional employment change', Small Business Economics, 9, 437-48.

Fritsch, M. and P. Mueller (2004), 'Effects of business formation on regional development over time', Regional Studies, 38, 961-75.

Fritsch, M. and P. Mueller (2008), 'The effect of new business formation on regional development over time: the case of Germany', Small Business Economics, 30, 15-29.

Fukuyama, F. (1995), Trust: The Social Virtues and Creation of Prosperity, New York: Free Press.

Galster, G. (1998), An Econometric Model of Metropolitan Opportunity Structure; Cumulative Causation among City Markets, Social Problems and Underserved Areas, Washington, DC: Fannie Mae Foundation and Urban Institute.

Granovetter, M. (1985), 'Economic action and social structure: the problems of embeddedness', American Journal of Sociology, 91, 481-510.

Guiso, L., P. Sapienza and L. Zingales (2004), 'The role of social capital in financial development', The American Economic Review, 94, 526-56.

Gulati, R. and M. Gargiulo (1999), 'Where do interorganizational networks come from?', American Journal of Sociology, 104, 1439-93.

Helmsing, A.H.J. (2001), 'Externalities, learning and governance: new perspectives on local economic development', Development and Change, 32, 277-308.

Holtz-Eakin, D. and C. Kao (2003), 'Entrepreneurship and economic growth: the proof is in productivity', Working Paper No. 50, Center for Policy Research, Syracuse University, New York.

Irwin, M., C. Tolbert and T. Lyson (1999), 'There is no place like home: nonmigration and civic management', Environment and Planning A, 31, 2223-38.

Jacobs, J. (1969), The Economy of Cities, New York: Random House. 
Jennings, E.T. and M.P. Haist (1998), 'Civic community, interest groups, and economic development in the States', paper presented at the annual meeting of the American Political Science Association, Boston, MA, 3-6 September.

Karlsson, C., B. Johansson and R.R. Stough (2001), 'Introduction: endogenous regional growth and policy', in B. Johansson, C. Karlsson and R.R. Stough (eds), Theories of Endogeneous Regional Growth. Lessons for Regional Policy, Berlin: Springer, pp. 1-13.

Karlsson, C. and K. Nyström (2007), Nyföretagande, näringslivsdynamik och tillväxt i den nya världsekonomin, Underlagsrapport $\mathrm{Nr} 5$ till Globaliseringsrådet, Regeringskansliet, Stockholm.

Kirzner, I. (1973), Competition and Entrepreneurship, Chicago, IL: University of Chicago Press.

Klette, T. and A. Mathiasen (1996), 'Job creation, job destruction and plant turnover in Norwegian manufacturing', Annales d'Economique et de Statistique, 41/42, 97-125.

Knack, S. and P. Keefer (1997), 'Does social capital have an economic payoff?', The Quarterly Journal of Economics, 112, 1251-88.

Koster, S. (2006), Whose Child. How Existing Firms Foster New Firm Formation: Individual Start-Ups, Spin-Outs and Spin-Offs, University of Groningen (diss.).

Koster, S. and C. Karlsson (2010), 'New firm formation and economic development in a globalizing economy', in C. Karlsson, B. Johansson and R.R. Stough (eds), Entrepreneurship and Regional Development. Local Processes and Global Patterns, Cheltenham, UK and Northampton, MA, USA: Edward Elgar, pp. 44-66.

Krugman, P. (1995), Development, Geography and Economic Theory, Cambridge, MA: The MIT Press.

Luger, M.I. and H.A. Goldstein (1991), Technology in the Garden: Research Parks in Regional Economic Development, Chapel Hill, NC: University of North Carolina Press.

Malecki, E.J. (1991), Technology and Economic Development: The Dynamics of Local, Regional and National Change, Harlow, Essex: Longman Scientific and Technical.

Malecki, E.J. (1993), 'Entrepreneurship in regional and local development', International Regional Science Review, 16, 119-53.

Malecki, E.J. (1998), 'How development occurs: local knowledge, social capital and institutional embeddedness', paper presented at the Annual Meeting of Southern Regional Science Association, Savannah, GA.

Markusen, A. (2004), 'Targeting occupations in regional and community economic development', Journal of the American Planning Association, 70, 253-68.

Martin, R. and P. Sunley (1996), 'Paul Krugman's geographical economics and its implications for regional development theory: a critical assessment', Economic Geography, 72, 259-92.

McGinn, N.F. (1996), 'Education, democratization, and globalization: a challenge for comparative education', Comparative Education Review, 40, 341-57.

McLeod, G. and M. Goodwin (1999), 'Space, scale and state strategy: rethinking urban and regional governance', Progress in Human Geography, 23, 503-27.

Miller, G. (1992), Managerial Dilemmas: The Political Economy of Hierarchy, New York: Cambridge University Press.

Morgan, K. (1997), 'The learning region: institutions, innovation and regional renewal', Regional Studies, 31, 491-503. 
Mueller, P. (2007), 'Exploiting entrepreneurial opportunities: the impact of entrepreneurship on growth', Small Business Economics, 28, 355-62.

Mueller, P., A.J. van Stel and D.J. Storey (2007), 'The effects of new firm formation on regional development over time: the case of Great Britain', Small Business Economics, 30, 59-71.

Myrdal, G. (1957), Economic Theory and Underdeveloped Regions, London: Duckworth Press.

Nahapiet, J. and S. Ghoshal (1998), 'Social capital, intellectual advantage and the organizational advantage', The Academy of Management Review, 23, 242-66.

North, D. (1990), Institutions, Institutional Change and Economic Performance, Cambridge: Cambridge University Press.

Ohmae, K. (1995), The End of the Nation State: The Rise of Regional Economies, New York: Free Press.

Ostrom, E. (1990), Governing the Commons: The Evolution of Institutions for Collective Action, Cambridge: Cambridge University Press.

Ostrom, E. (2005), Understanding Institutional Diversity, Princeton, NJ: Princeton University Press.

Porter, M.E. (1986), Competition in Global Industries, Cambridge, MA: Harvard Business School Press.

Porter, M.E. (1990), The Competitive Advantage of Nations, New York: Macmillan.

Portes, A. (1998), 'Social capital: its origins and applications in modern sociology', Annual Review of Sociology, 24, 1-24.

Putnam, R.D. (with R. Leonardi and R.Y. Nanetti) (1988), Making Democracy Work, Princeton, NJ: Princeton University Press.

Putnam, R.D. (1993), 'What makes democracy work?', National Civic Review, 82, $101-9$.

Putnam, R.D. (1995), 'Bowling alone: America's declining social capital', Journal of Democracy, VI, 65-78.

Rees, J. (2001), 'Technology and regional development: theory revisited', in B. Johansson, C. Karlsson and R.R. Stough (eds), Theories of Endogeneous Regional Growth. Lessons for Regional Policy, Berlin: Springer, pp. 94-110.

Rhodes, R.A.W. (1996), 'The new governance: governing without government', Policy Studies, XLIV, 652-67.

Rhodes, R.A.W. (1997), Understanding Governance. Policy Networks, Governance, Reflexivity and Accountability, Buckingham: Open University Press.

Rosenberg, N. (1994), Exploring the Black Box: Technology, Economics and History, Cambridge: Cambridge University Press.

Rosenfeld, S.A. (1997), 'Bringing business clusters into the mainstream of economic development', European Planning Studies, 5, 3-24.

Sabatini, F. (2008), 'Social capital and the quality of economic development', KYKLOS, 61, 466-99.

Saxenian, A. (1994), Regional Advantage: Culture and Competition in Silicon Valley and Route 128, Cambridge, MA: Harvard University Press.

Scarpetta, S. et al. (2002), 'The role of policy and institutions for productivity and firm dynamics. Evidence from micro and industry data', Working Paper No. 329, OECD Economics Department, OECD, Paris.

Schmitz Jr, J.A. (1989), 'Imitation, entrepreneurship and long-term growth', Journal of Political Economy, 97, 721-39.

Scott, A.J. and M. Storper (1992), 'Regional development reconsidered', in 
H. Ernste and V. Meier (eds), Regional Development and Contemporary Industrial Response: Extending Flexible Specialization, London: Belhaven Press, pp. 3-24.

Skott, P. and P. Auerbach (1995), 'Cumulative causation and the "new" theories of economic growth', Journal of Post Keynesian Economics, 17, 381-402.

Stimson, R.J., R.R. Stough and B.H. Roberts (2006), Regional Economic Development. Analysis and Planning Strategy, 2nd edn, Berlin: Springer.

Tao, J. and R.C. Feiock (1999), 'Directing benefits of need: evaluating the distributive consequences of urban economic development', Economic Development Quarterly, 13, 55-66.

van Stel, A.J. and D.J. Storey (2004), 'The link between firm birth and job creation: is there a upas tree effect?', Regional Studies, 38, 893-909.

van Stel, A.J. and K. Suddle (2007), 'The impact of new firm formation on regional development in the Netherlands', Small Business Economics, 30, 31-47.

Vazquez-Barquero, A. (2002), Endogenous Development. Networking, Innovation, Institutions and Cities, London: Routledge.

Westlund, H. (2006), Social Capital in the Knowledge Economy: Theory and Empirics, Berlin: Springer.

Williamson, O.E. (1979), 'Transaction-cost economics: the governance of contractual relations', Journal of Law and Economics, 22, 233-61.

Wong, P.K., Y.P. Ho and E. Autio (2005), 'Entrepreneurship, innovation and economic growth: evidence from GEM data', Small Business Economics, 24, $335-50$.

Zak, P.J. and S. Knack (2001), 'Trust and growth', The Economic Journal, 111, 295-331. 